\title{
Direitos Humanos e Avaliação Psicológica: Indissociabilidade do Compromisso Ético-Político Profissional
}

\author{
Pedro Paulo Gastalho de Bicalho ${ }^{1}$ \\ ${ }^{1}$ Universidade Federal do Rio de Janeiro, RJ, Brasil.
}

\author{
Erick da Silva Vieira ${ }^{1}$ \\ ${ }^{1}$ Universidade Federal do Rio de Janeiro, RJ, Brasil.
}

\begin{abstract}
Resumo: O artigo é efeito de análises da dimensão dialógica do ato de avaliar a partir da perspectiva de produção mútua: do que (ou de quem) avalia e o que (ou quem) é avaliado e, assim, apresenta reflexões acerca da indissociabilidade entre direitos humanos e avaliação psicológica, fundamentada na discussão crítica que, historicamente, aponta para a necessidade de sua contextualização e da concepção desta enquanto processo. Julga-se importante afirmar a inseparabilidade entre as dimensões política e epistemológica do conhecimento e o modo como tal posicionamento produz diferentes métodos, objetivos e práticas e, assim, aponta-se para uma forma de intervenção que se afasta das lógicas de individualização, desde a formulação e validação dos instrumentos até o contexto de aplicação e análise, afirmando a análise das demandas e de implicações como pressuposto. Como resultado, o estudo proporcionou o entendimento de que o exercício de direitos humanos junto ao processo de avaliação psicológica deve fazer-se presente e efetivo não somente na construção de seus instrumentos e em seus requisitos técnicos, como também em sua manipulação e aplicação, ou seja, na postura éticopolítica de quem executa a avaliação, levando-se em consideração que a subjetividade dos brasileiros é também (e principalmente) produzida pelos processos históricos de desigualdade e violência, efeitos de quatrocentos anos de colonização e escravização.
\end{abstract}

Palavras-chave: Psicologia, Avaliação Psicológica, Direitos Humanos.

\section{Human Rights and Psychological Assessment: Inseparability of the Professional Ethical-Political Commitment}

\begin{abstract}
The current article aimed to analyze the dialogical dimension of the assessment act from the mutual production perspective: what (or who) evaluates and what (or who) is evaluated and, therefore, presents reflections on the inseparability between human rights and psychological assessment, based on the critical discussion that, historically, points to the necessity of its contextualization and the understanding of this concept as a process. We find it important to affirm that the inseparability between the political and epistemological dimensions of knowledge produces different methods, objectives and practices and, therefore, points to a form of intervention that goes to a different direction from the logics of individualization, including the formulation and validation of instruments and the context of application and analysis, affirming the analysis of the demands and implications as a presupposition. As a result, the study provided the understanding that the exercise of human rights along with the process of psychological assessment should be present and effective not only in the construction of its instruments and technical requirements, but also in its manipulation and application - in other words, in the ethical-political stance of those who carry out the assessment, taking into consideration that the subjectivity of Brazilians is also (and mainly) produced by historical processes of inequality and violence, effects of four hundred years of colonization and enslavement.
\end{abstract}

Keywords: Psychology, Psychological Assessment, Human Rights. 


\title{
Derechos Humanos y Evaluación Psicológica: Inseparabilidad del Compromiso Ético-Político Profesional
}

\begin{abstract}
Resumen: El artículo es efecto de análisis de la dimensión dialógica del acto de evaluar a partir de la perspectiva de producción mutua: de lo que (o de quien) evalúa y lo que (o quién) es evaluado y, así, presenta reflexiones acerca de la inseparabilidad entre derechos humanos y evaluación psicológica, fundamentada en la discusión crítica que, históricamente, apunta a la necesidad de su contextualización y de la concepción de ésta en cuanto proceso. Se considera importante afirmar la inseparabilidad entre las dimensiones política y epistemológica del conocimiento y el modo como tal posicionamiento produce diferentes métodos, objetivos y prácticas y, por lo tanto, se apunta a una forma de intervención que se aparta de las lógicas de individualización, incluyendo la formulación y la validación de los instrumentos hasta el contexto de aplicación y análisis, afirmando el análisis de las demandas y de la implicación como presupuesto. Como resultado, el estudio proporcionó el entendimiento de que el ejercicio de derechos humanos junto al proceso de evaluación psicológica debe hacerse presente y efectivo no sólo en la construcción de sus instrumentos y en sus requisitos técnicos, sino también en su manipulación y aplicación, o en la postura ético-política de quien ejecuta la evaluación, teniendo en cuenta que la subjetividad de los brasileños es también (y principalmente) producida por los procesos históricos de desigualdad y violencia, efectos de cuatrocientos años de colonización y esclavización.
\end{abstract}

Palabras clave: Psicología, Evaluación Psicológica, Derechos Humanos.

\section{Introdução}

$\mathrm{O}$ ato de avaliar, em qualquer circunstância, seja nas ciências humanas ou naturais, na Psicologia ou em qualquer outro campo da ciência, pressupõe uma importante dimensão dialógica, na medida em que envolve concepções acerca de quem avalia e de quem é avaliado (Bicalho, 2013a). Tal postura político-epistemológica - fundamento de todo o processo - pode definir estas instâncias relacionais enquanto distintas, na medida em que o avaliador busca realizar uma coleta de informações acerca do avaliando, a fim de subsidiar e orientar ações em relação a este; ou reconhecê-las enquanto produzidas mutuamente, enquanto ambos são afetados pela própria situação da avaliação, o que aponta para o que podemos chamar de "colheita" de dados, ou seja, uma prática de caráter construtivista (Barros, \& Kastrup, 2015). Tal distinção não se restringe a mera troca de palavras; antes, determina métodos, objetivos e práticas que, em conjunto, produzem efeitos em todos os envolvidos.

Em se tratando especificamente da ciência psicológica e de sua constituição enquanto saber, o processo de avaliação apresenta-se, sob uma perspectiva histórica, enquanto um mecanismo legitimado de produção de verdades acerca de determinados sujeitos/grupos na medida em que tomava resultados de testagens como avaliações estáticas, modelando representações sociais acerca destes e dando origem às diversas taxonomias (Ramos, \& Bicalho, 2012). Trata-se, portanto, do que Patto (1997) nomeia de "artimanha do poder", na medida em que se reconhecem certos fenômenos como individuais (chamados de "deficiências de capacidade") e não enquanto analisadores de processos múltiplos de produção de desigualdade de direitos, determinados historicamente, o que acaba por reproduzir tais processos e fomentar práticas de exclusão social (Reppold, 2011). Em vistas de desenvolver uma visão crítica acerca do psicodiagnóstico, a autora aponta a extrema importância de destacar o reconhecimento da dimensão política de tal processo:

O que está em pauta não são os testes em si mesmos, mas uma discussão teórica de caráter muito mais amplo: o da própria concepção de ciência, de Homem e de sociedade que lastreia uma Psicologia que está na base da criação de instrumentos para fins de avaliação e classificação de indivíduos e grupos (Patto, 1997, p. 52). 
Fundamentada em argumentos como a reificação dos seres humanos, a transposição metodológica das ciências naturais para as ciências humanas e a inseparabilidade entre as dimensões política e epistemológica do conhecimento (Patto, 1997), a discussão crítica acerca da avaliação psicológica apontou para a necessidade de sua contextualização e da concepção desta enquanto processo; ou seja, tornava-se de suma importância refletir acerca "dos conteúdos; da definição de inteligência e de personalidade em que se apoiam; do critério estatístico e adaptativo de normalidade que lhes serve de base; da situação de testagem propriamente dita; da teoria do conhecimento a partir da qual eles são gerados" (Patto, 1997, p. 50). A mesma discussão é constituída ao analisar o processo de pesquisa e os efeitos de verdade por ele produzidos (David, Pedro, \& Bicalho, 2014). Desta forma, reconhecer a dimensão política dos processos inferenciais significa destacar os múltiplos requisitos que os atravessam, do início ao fim, desde sua formulação e validação até o contexto de aplicação, discussão e análise. Configura-se, deste modo, a testagem como uma etapa da avaliação, e não sinônimo desta: "A avaliação psicológica é compreendida como um amplo processo de investigação, no qual se conhece o avaliado e sua demanda, com o intuito de programar a tomada de decisão mais apropriada do psicólogo" (Conselho Federal de Psicologia, 2013, p. 11 - grifos nossos).

$\mathrm{Na}$ medida em que oferece suporte para a tomada de decisão da(o) profissional psicóloga(o) (e não a substitui), a dimensão ética da avaliação torna-se evidente, o que aponta para o fato de que, além dos requisitos técnicos, tanto o desenvolvimento de instrumentos quanto sua utilização deve ser permeada por uma conduta consoante com os princípios do código de ética da profissão (Resolução № 010, 2005); entre estes, destacam-se:

II. O psicólogo trabalhará visando promover a saúde e a qualidade de vida das pessoas e das coletividades e contribuirá para a eliminação de quaisquer formas de negligência, discriminação, exploração, violência, crueldade e opressão.

III. O psicólogo atuará com responsabilidade social, analisando crítica e historicamente a realidade política, econômica, social e cultural.

(Resolução No 010, 2005, p. 7).
Ao indicar a responsabilidade social do profissional psicólogo - fundamentada em uma postura crítica e histórica -, o código de ética apresenta-se em consonância aos princípios dos direitos humanos, aqui entendidos não como interlocução jurídica e natural, mas concebidos "a partir de nossas práticas, como agenciamentos e efeitos que por elas são produzidos" (Bicalho, \& Barbosa, 2014a, p. 169). Logo, tanto o desenvolvimento de instrumentos quanto sua utilização no processo de avaliação psicológica, enquanto prática exclusiva dos profissionais de Psicologia, deve reconhecer o caráter complexo dos sujeitos, coletividades e sociedade com os quais se relaciona - assim como dos direitos que lhes são devidos -, o que significa pôr em análise contínua práticas e saberes, cientes tanto de suas potencialidades como de suas limitações - em outras palavras, de suas humanidades.

Assim, ao adotar a avaliação psicológica enquanto processo ético-político, o presente artigo tem por objetivo ratificar a necessidade da indissociabilidade dos direitos humanos aos diferentes momentos desta prática profissional, através da elucidação de noções incluídas nos contextos da pesquisa acadêmica e da prática psicológica (Bicalho, Magalhães, Cassal, \& Geraldini, 2012). Somada a tais noções, integra à discussão a trajetória histórica da pauta dos direitos humanos em sua relação com a avaliação psicológica nas resoluções oficiais da categoria, na medida em que é afirmada a ideia de que "fomentar a discussão da interface entre avaliação psicológica e direitos humanos é fundamental para o estabelecimento de bases mais objetivas sobre as quais a atuação do psicólogo deve orientar-se" (Costa, \& Nardi, 2013, p. 125).

\section{Direitos humanos e Avaliação Psicológica}

Conceituados como necessidades humanas fundamentais para que as pessoas sobrevivam e se desenvolvam (Bicalho, 2013b), os direitos humanos devem ser protegidos não somente por ordenamentos jurídicos que proponham "um mínimo de regras para evitar absurdos, a partir da questão de como coibir novas atrocidades" (Bicalho, Cassal, Magalhães, \& Geraldini, 2009, p. 22). Direitos humanos, para além de tratados, convenções e legislações, devem ser transversalizados às práticas profissionais, pressupondo o seu efetivo exercício no cotidiano.

Terminada a Segunda Guerra Mundial foi criada em 1945, pela Carta de São Francisco, a Organização 
das Nações Unidas (ONU), propondo-se à comunidade internacional a discussão e o resgate da noção de direitos humanos (Bicalho, 2005). Tais propostas efetivaram a promulgação, em 1948, de uma declaração que, embora destituída de força legal, constitui-se como uma carta de recomendações, composta por um preâmbulo com sete considerações e mais 30 artigos $^{1}$. Os 21 primeiros abrangem direitos civis e políticos (direitos e garantias do indivíduo), os sete seguintes tratam dos direitos econômicos, sociais e culturais e os dois últimos, respectivamente, da responsabilidade do indivíduo em relação à sua comunidade e a vedação de qualquer interpretação da declaração de modo a "destruir os direitos e liberdades nela estabelecidos".

Foram produzidos ainda, em 1966, dois pactos exigíveis dos países signatários (não apenas recomendações): o Pacto Internacional dos Direitos Civis e Políticos e o Pacto Internacional dos Direitos Econômicos, Sociais e Culturais, com o objetivo de criação de instrumentos para efetiva aplicação desses direitos. Cada região, deste modo, criou organismos internacionais com fins de regular os chamados direitos humanos, como a Corte Interamericana e a Corte Europeia de Direitos Humanos e a Declaração de Direitos e Deveres dos Povos Africanos, além de declarações, tratados e convenções específicos, como a Convenção para a Prevenção e Repressão ao Crime de Genocídio (1948), a Convenção Relativa à Proteção do Patrimônio Mundial, Cultural e Natural (1972), a Convenção sobre a Eliminação de todas as formas de Discriminação contra a Mulher (1979), a Convenção contra a Tortura e outros Tratamentos ou Penas Cruéis, Desumanos ou Degradantes (1984), a Convenção sobre os Direitos da Criança (1989) e a Convenção sobre a Diversidade Biológica (1992), dentre outras.

Os órgãos internacionais de supervisão de Direitos Humanos passaram a se tornar realidade somente após a I Conferência Internacional, em 1968, no Teerã, resultando em obrigatoriedade para os Estados em 1993, na II Conferência Internacional de Direitos Humanos, em Viena, a partir da perspectiva de interdependência entre as diversas convenções e da internacionalização das ações, denominada direito sem fronteiras (Bicalho, 2015). A proteção internacional dos Direitos Humanos consiste em regras internacionais que impõem a obrigatoriedade do respeito aos direitos humanos pelas nações ${ }^{2}$, bem como a supervisão no cumprimento de tais medidas.

Após a Segunda Guerra Mundial, três Sistemas de Proteção dos Direitos da Pessoa Humana foram implantados na esfera internacional: (a) O Sistema Global, pioneiro na internacionalização dos Direitos Humanos e fundamentado juridicamente pela Carta da ONU de 1945 - a qual contém normas que determinam a importância de promover e respeitar os direitos humanos e as liberdades fundamentais, porém, sem definir o conteúdo dessas expressões, o que só veio a ocorrer com precisão na Declaração Universal dos Direitos Humanos, de 1948; e, composto também, pelas diversas Convenções, Pactos e Planos de Ação elaborados no âmbito das Nações Unidas e ratificados pelos Estados signatários; (b) Os sistemas em nível regional, surgidos nos continentes americano, europeu e africano com objetivo de monitorar o respeito aos direitos humanos nos respectivos continentes; e, (c) O sistema destinado à proteção das pessoas em situação de conflito armado denominado Direito Internacional Humanitário.

Durante a década de 1970 surgiram centros de defesa de Direitos Humanos no Brasil, agindo diretamente com os movimentos pró-democratização, como as "Diretas Já”, desembocando na promulgação, em 1988, da atual constituição do país, a qual introduziu um modelo de gestão das políticas sociais públicas fundado na descentralização político-administrativa e na democracia participativa.

Em decorrência do estabelecido na Constituição, o Brasil aderiu aos Pactos Internacionais de Direitos Civis e Políticos, de Direitos Econômicos, Sociais e Culturais, ratificados em 1992, à Declaração Universal dos Direitos Humanos de 1948 e, em 1989, à Convenção Contra a Tortura e Tratamentos ou Penas Cruéis, Desumanos ou Degradantes, os quais são os documentos internacionais, entre outros, de maior importância, resgatando e valorizando a dignidade humana e colocando-a como valor fundamental no que se refere à inviolabilidade do direito a vida, à liberdade, à segurança e à igualdade. De acordo com seu artigo $5^{\circ}$,

\footnotetext{
${ }^{1}$ Disponível em <http://www.onu.org.br/img/2014/09/DUDH.pdf>.

${ }^{2}$ Um exemplo é a criação dos tribunais ad hoc, ocasionalmente em função de certas questões locais, como na ex-Iugoslávia, na Tanzânia, na Ruanda e mais tarde, a criação do Tribunal Penal Internacional Permanente, em Roma, ainda aguardando decreto de ratificação. A dificuldade no desenvolvimento deste tema encontra-se no fato de que o Direito Internacional se torna válido apenas para os países que dele fazem parte. Deste modo, o cumprimento do tratado varia de acordo com o Estado Nacional.
} 
os direitos e garantias fundamentais - vida, liberdade, igualdade, propriedade e segurança - são considerados de aplicação imediata, além de serem assegurados como cláusulas pétreas constitucionais, ou seja, não podem ser modificadas nem mesmo por emendas à Constituição. Tais garantias são classificadas como ativas e não ativas. As primeiras, que asseguram a efetividade do direito e, as segundas, a efetividade das garantias não ativas do direito, sendo ainda conhecidas como "remédios constitucionais", os quais podem configurar ações populares, mandados de segurança, mandatos de injunção, habeas corpus e habeas data.

De acordo com Herkenhoff (1997), a expressão "Direitos Humanos" pode ser identificada com a preocupação e o reconhecimento de tais direitos desde a Antiguidade, citando o Código de Hamurabi, no século XVIII a.C., na Babilônia; os pensamentos do imperador egípcio Amenófis IV, século XIV a.C.; a peça Antígona, de Sófocles, na Grécia em V a.C.; as ideias de Platão, na Grécia, no século IV a.C.; o Direito Romano, e várias outras civilizações e culturas ancestrais, que em muito contribuíram, segundo ele, para a criação da ideia de Direitos Humanos, além de pensadores modernos e contemporâneos, como Kant, Santo Agostinho e Santo Tomás de Aquino, este último tendo questionado o poder atribuído aos reis durante o Absolutismo, argumentando que toda a humanidade possuía direitos naturais, os quais seriam dados por Deus.

Herkenhoff (1997) enfatiza ainda que, embora a preocupação com a proteção da integridade da pessoa humana seja secular, pois, segundo ele, faz parte da própria natureza humana, a simples técnica de estabelecer, em constituições e leis, a limitação do poder, embora importante, não assegura, por si só o respeito aos Direitos Humanos. Como cita o autor:

Assistimos em épocas passadas e estamos assistindo, nos dias de hoje, ao desrespeito dos Direitos Humanos em países onde eles são legais e constitucionalmente garantidos. Mesmo em países de longa estabilidade política e tradição jurídica, os Direitos Humanos são, em diversas situações concretas, rasgados e vilipendiados (p. 47).

Trindade (2002) chama a atenção para o fato de que, em nome dos ideais de igualdade e fraternidade contidos nas inúmeras concepções de direitos humanos, foi erigido, por meio do AI-5, um dos regimes que mais crimes cometeu contra os mesmos direitos em toda a história brasileira. Ou mesmo o Main Kampf de Adolf Hitler, livro sobre o qual ele mesmo escrevera: "Os direitos humanos estão acima dos direitos do Estado”.

Talvez não tenha havido opressor nos últimos duzentos anos, ao menos no Ocidente, que não tivesse, em nenhum momento, lançado mão da linguagem dos direitos humanos. Hitler foi apenas mais um a adotar esse procedimento. [...] Por que tem sido tão fácil falar em direitos humanos e por que essa expressão tornou-se assim maleável, tão complacente e moldável, a ponto de a vermos ser pronunciada sem rubor pelos mais insólitos personagens? O que significa ela exatamente? (Trindade, 2002, pp. 5; 16).

A Psicologia, no período pós-regulamentação e atravessada pelo contexto de redemocratização do país, assume o discurso do compromisso social como norte político (Bock, 1999), aproximando-se para a perspectiva de um campo de saber politizado e engajado, acompanhando as mudanças na conjuntura política nacional e internacional (Yamamoto, 2007), sempre marcada pela contradição de ter sido estabelecida como prática intimista e individualizada (Bicalho, \& Barbosa, 2014b). A crítica trazida à época no debate interno da Psicologia dizia respeito a que população o psicólogo e a psicóloga deveriam atender e a que projeto de sociedade serviam. Um estudo expressivo na época (Yamamoto, 2007) constata que apenas $15 \%$ da população brasileira tinha acesso à área de maior expressão da Psicologia na época, a clínica, e questiona: "os demais $85 \%$ não necessitam desse serviço?” (Yamamoto, 2007, p. 30). Vê-se, a partir de então, um crescente questionamento à predominância da clínica e à pouca participação da Psicologia como área do saber na construção política de uma sociedade mais igualitária.

Nas décadas seguintes cresce o envolvimento da categoria com questões políticas, com a ocupação e participação em sindicatos, a expansão do sistema conselhos, o envolvimento com a luta antimanicomial e o movimento da saúde (Yamamoto, 2007), além da avaliação dos rumos da categoria a partir de pesquisas sobre a atuação do psicólogo realizadas pela academia ou em conjunto com os conselhos (Yamamoto, \& Amorim, 2010). Inicia-se, assim, uma maior articulação entre as práticas produzidas pela Psicologia e as demandas sociais da população brasileira, com a qual a profissão estava sendo convocada a dialogar. 
Nos anos 80 do século XX, durante o período de redemocratização do país, o então Código de Ética Profissional, publicado em 1987 "define as responsabilidades, direitos e deveres dos psicólogos de acordo com os princípios da Declaração Universal dos Direitos Humanos" (Conselho Regional de Psicologia de São Paulo, 2011). Logo em seguida acontece o Congresso Unificado dos Psicólogos, em que se discutiria "a concepção corporativista e eleições diretas no Conselho Federal de Psicologia (CFP) por meio de chapas com programa definido" (Conselho Regional de Psicologia de São Paulo, 2011). Nesse sentido, a oficialização do primeiro Código de Ética pós-ditadura e a reestruturação do Sistema Conselhos, criado durante o regime militar, refletem a democratização da relação entre a profissão e a população, ao garantir que os interesses e as demandas desta estão sendo representados na atuação profissional (Conselho Regional de Psicologia de São Paulo, 2011).

Ainda durante o final da década de 1980, o Brasil presencia um dos maiores marcos no início da transformação dos cuidados em saúde mental quando, em dezembro de 1987, as ruas de Bauru, cidade do interior do estado de São Paulo, são tomadas pela afirmação da luta por uma sociedade sem manicômios em função do II Congresso Nacional dos Trabalhadores em Saúde Mental. Esse marco é consolidado pela publicação do manifesto, também conhecido como "A Carta de Bauru", a qual simbolizava a luta de trabalhadores, usuários e outros ativistas da saúde mental por uma sociedade marcada pela luta antimanicomial (Conselho Regional de Psicologia de São Paulo, 2011).

Nesse período, constata-se um crescimento da presença de psicólogos e psicólogas nas políticas públicas - em especial nas de saúde - fato esse que fez com que os profissionais se mobilizassem diante de teorias e metodologias que não se adequavam às novas necessidades, referentes ao compromisso social da profissão.

\section{Avaliação Psicológica e Direitos Humanos}

Tomando como ponto de análise a produção científica das ciências humanas e da saúde a partir da avaliação psicológica, reconhecer quem está sendo público-alvo desta prática é de suma importância na discussão acerca dos direitos humanos. Se reconhecemos o poder conferido à tal produção - e longe estamos de negá-lo, contudo lançar luz sobre ele -, torna-se necessário pensar quem são os grupos de referência, os ditos "saudáveis" ou "normais" (Canguilhem, 2009), na medida em que "normal e patológico são categorias que distinguem, no plano social, o que é prescrito ou aceito daquilo que é proscrito ou recusado" (Bezerra Junior, 2006, p. 91). Em sua leitura da obra clássica do médico e filósofo, este autor aponta a polissemia do termo:

A primeira toma o termo como um fato: normal é aquilo que é mais prevalente, o que estatisticamente se apresenta como mais constante, mais frequente, numa determinada população; é algo detectado pela observação e objetivamente mensurável. Ao lado desta definição existe, imersa no uso habitual dessa palavra, uma outra, na qual o normal é concebido não apenas como aquilo que "é", mas como aquilo que "deve ser" (Bezerra, 2006, pp. 97-98).

Desta forma, é necessário atentar para as situações nas quais o grau de normatividade se torna prevalente, ou seja, quando o critério normativo se encontra pautado em um valor, e não em um fato (Bezerra, 2006). Dada a impossibilidade de conceber a realidade social por meio de metáforas biológicas ou em analogia à normatividade da vida, uma vez que "[...] o ser vivo e o meio, considerados separadamente, não são normais; [...] é sua relação que os torna normais um para o outro" (Canguilhem, 2009, pp. 112-113), o autor aponta a complexidade das formas de organização social, "nas quais os valores são contingentes" (p. 105).

É exatamente a ideia de caráter contingencial, histórico e multideterminado dos próprios conceitos de saúde e normalidade que precisa se fazer presente no contexto da prática de avaliação psicológica, na medida em que classe, cor, território, e tantos outros atravessamentos situam-nos - especialmente no Brasil, país em que a colonização e a escravização são processos de subjetivação estruturantes da população sob formas atualizadas de diversas espécies de violência e desigualdades - e, quando não colocados sob análise, discriminam outros grupos que não atendem às normas padronizadas dos instrumentos. É por este motivo que, quando no processo de atualização destas, deve-se considerar diferentes amostras, que "deverão contemplar, preferencialmente, a representação demográfica de distintas regiões geopolíticas brasileiras" (Resolução No 009, 2018, art. 22). 
Assim, a utilização de um teste psicológico deve sempre estar alinhada, por um lado, com os objetivos para os quais foi construído (indicadores de validade) e, por outro, com os objetivos e contextos do processo de avaliação como um todo (demanda). Decorre daí a responsabilidade depositada tanto no profissional que desenvolve os testes psicológicos quanto no que aplica tais instrumentos em processos de avaliação. Ao primeiro, cabe a tarefa de fornecer informações nítidas e suficientes sobre a teoria que fundamenta o instrumento (fundamentação teórica), demonstrar que os escores obtidos com o teste se relacionam com a teoria e/ou com os dados da experiência (indicadores de validade), estimar o nível em que um teste está livre de erros não controláveis (indicadores de fidedignidade) e descrever manifestamente as condições e procedimentos dentro dos quais o instrumento se torna válido e fidedigno (padronização). Já ao segundo, compete o conhecimento suficiente para decodificar as informações técnicas contidas no manual, conciliando-as com a situação de demanda da avaliação, ou seja, reconhecer que os resultados mensurados pelo teste integram processos mais abrangentes e têm grande impacto para as pessoas, grupos e sociedade, cabendo-lhes

[...] considerar e analisar os condicionantes históricos e sociais e seus efeitos no psiquismo, com a finalidade de servirem como instrumentos para atuar não somente sobre o indivíduo, mas na modificação desses condicionantes que operam desde a formulação da demanda até a conclusão do processo de Avaliação Psicológica (Resolução No 007, 2003, p. 3)

No que diz respeito ao grande impacto causado pelos resultados de avaliações psicológicas e sua relação com a pesquisa acadêmica, ou seja, da fundamentação teórica, formulação, validação e padronização dos instrumentos, uma noção que remonta a esta discussão consiste no amplo emprego da Análise Fatorial Confirmatória Multigrupo (AFCMG) na validação de instrumentos psicométricos e em estudos de comparação de grupos (Damasio, 2013). Para a Psicologia, a Análise Fatorial é "uma das principais ferramentas no desenvolvimento, na avaliação, no refinamento e no uso de testes psicométricos" (Damasio, 2013, p. 211), uma vez que possibilita a identificação das variáveis latentes da estrutura de um instrumento, ou seja, os fatores que compõem a variância explicada de dado instrumento acerca de determinado construto: tal análise pode ser exploratória, quando não há definição prévia acerca de quais variáveis compõem cada fator e da quantidade de fatores; ou confirmatória, quando a fundamentação teórica possibilita uma estruturação anterior à análise acerca do número e da composição das variáveis latentes, com o intuito de, como o nome sugere, confirmá-la.

Por sua vez, a AFCMG avalia a chamada invariância de medida, ou seja, "em que medida a configuração e os parâmetros de determinado instrumento psicométrico são invariantes, ou equivalentes, para diferentes grupos de pessoas" (Damasio, 2013, p. 212). Diferentes modelos podem ser adotados na análise de tal invariância, como a invariância configural, relacionada à forma, ou seja, avaliar se a estrutura fatorial de determinado instrumento é igual entre diferentes grupos; invariância métrica, a qual visa verificar se os itens que compõem determinado fator apresentam a mesma importância (mesma carga fatorial) para diferentes grupos; invariância escalar, na qual se questiona a possibilidade de os escores de um grupo poderem ser comparados com os escores de outros grupos ou se a existência de vieses de resposta impossibilitam essa comparação; além de outros modelos mais específicos, conforme aponta o autor.

O emprego de tal técnica estatística justifica-se pela necessidade de assegurar a confiabilidade das comparações posteriores à análise dos dados de grupos distintos, conforme indica o mesmo autor:

Isso porque, se o instrumento estiver enviesado para um ou outro grupo, quaisquer diferenças encontradas entre os grupos podem estar relacionadas não às diferenças reais nos níveis de traço latente dos sujeitos, mas sim a parâmetros não equivalentes do instrumento utilizado. [...] Em consequência, inferências sobre as diferenças entre os grupos podem estar equivocadas (Nimon, \& Reio, 2011 como citado em Damasio, 2013, p. 213).

A preocupação com o equívoco acerca das inferências levantadas e com a necessidade de equiparação de medidas na validação de um instrumento associa-se diretamente à fuga de resultados reprodutores de estigmatizações de grupos específicos. A ideia de "calibre adequado", fundamento da AFCMG, 
aponta para a construção de um aparato técnico no processo de avaliação que reconhece as limitações de seus métodos e estimula a constante revisão destes, de modo a possibilitar uma produção científica própria e confiável, principalmente no que diz respeito à tradução e validação de instrumentos internacionais, tendo em vista que "as normas relativas a esses países, entre outras, induziam a uma avaliação não condizente com indivíduos de outros grupos sociais que não os do contexto de origem dos instrumentos" (Costa, \& Nardi, 2013, p. 127).

Portanto, quando nos propomos a ser agentes da prática de avaliação, pô-la em análise é condição de sua eficácia, ao dedicar "atenção aos procedimentos éticos implícitos e considerando as eventuais limitações da avaliação" (Conselho Federal de Psicologia, 2013, p. 14). Como exposto anteriormente, o entendimento e exercício de direitos humanos neste processo deve fazer-se presente e efetivo não somente na construção de seus instrumentos e em seus requisitos técnicos, como também em sua manipulação e aplicação, ou seja, na postura ética de quem a executa (Bicalho, \& Reishoffer, 2017). Assim, torna-se impossível não envolver nessa discussão a formação dos profissionais psicólogos, na medida em que se estimule uma visão crítica - e não predominantemente técnica (Bicalho et al., 2009; Patto, 1997) - acerca do processo de avaliação e sua dimensão política, uma vez que "em um país caracterizado por diferenças sociais, culturais e econômicas tão marcantes como o Brasil, o trabalho de revisão de técnicas psicológicas deve ser constante, e os profissionais formados na área precisam ser capazes de realizar tal revisão (Costa, \& Nardi, 2013, p. 133).

De modo semelhante, afirma-se a indissociabilidade entre as pesquisas classificadas como quantitativas ou qualitativas. "As formas ou qualidades são expressão da luta entre as forças, de quanta de força, por isso são indissociáveis das quantidades. Nessa mesma direção, não há como acessar o plano das forças sem a avaliação das qualidades, das formas" (Cesar, Silva, \& Bicalho, 2013, p. 364). A crítica direciona-se a uma noção de quantidade como conceito abstrato que tende à anulação da diferença e a uma noção de qualidade que não seja expressão da relação entre as forças. O que nos interessa "é, do ponto de vista, da própria quantidade, a irredutibilidade da diferença de quantidade à igualdade" (Deleuze, 1976, p. 36).

Avaliação psicológica, assim, deve ser entendida não como forma ritual e científica de fixar diferenças individuais, amarrando cada indivíduo à sua própria singularidade e indicando a aparição de uma nova modalidade de poder "em que cada um recebe como status permanente uma individualidade estatutariamente ligada aos traços, às medidas, aos desvios e às avaliações que caracterizam o indivíduo e fazem dele, de todo modo, um caso" (Reishoffer, \& Bicalho, 2017, p. 35).

Ao contrário, avaliar diz respeito à inferência ao modo como a vida se expande ou se apequena. Não basta simplesmente afirmar ou negar outra noção de quanti ou quali, mas pensar estratégias de articulação dos efeitos da pesquisa (e da avaliação) com a própria vida. Interessa nesse sentido, no caso de instrumentos como os testes psicológicos, menos defini-los como intercessores quanti ou quali, e mais, pensá-los como mobilização de quantidades de força, como efeitos que atualizam sujeitos e mundos.

\section{Dois mil e dezoito: encontros e encaminhamentos}

O ano de 2018, três décadas após a promulgação da "Constituição cidadã", sublinha os 70 anos da Declaração Universal dos Direitos Humanos e, no Sistema Conselhos de Psicologia, os 15 anos do Sistema de Avaliação de Testes Psicológicos (Satepsi). A "coincidência de datas" assinala a publicação da Resolução no 09 de 2018 do Conselho Federal de Psicologia, que "estabelece diretrizes para a realização de Avaliação Psicológica no exercício profissional da psicóloga e do psicólogo, regulamenta o Satepsi e revoga as Resoluções $n^{\circ}$ 002/2003, no 006/2004 e n ${ }^{\circ} 005 / 2012$ e Notas Técnicas $n^{\circ}$ 01/2017 e 02/2017". Publicação que, de forma efetiva, regulamenta a indissociabilidade entre avaliação psicológica e direitos humanos e afirma, em seus considerandos, a função social da Psicologia e o compromisso ético das psicólogas e psicólogos. Resolução que possui um item denominado "Justiça e proteção dos direitos humanos na avaliação psicológica”, o qual possui artigos que diretamente afirmam que "na Avaliação Psicológica, a psicóloga ou psicólogo deverão considerar os princípios e artigos previstos no Código de Ética Profissional das psicólogas e dos psicólogos, bem como atender aos requisitos técnicos e científicos" (Resolução No 009, 2018, art. 30), e ainda que

[...] à psicóloga ou ao psicólogo, na produção, validação, tradução, adaptação, normatização, comercialização e aplicação de testes psicológicos, é vedado: a) realizar atividades que caracterizem 
negligência, preconceito, exploração, violência, crueldade ou opressão; b) induzir a convicções políticas, filosóficas, morais, ideológicas, religiosas, raciais, de orientação sexual e identidade de gênero; c) favorecer o uso de conhecimento da ciência psicológica e normatizar a utilização de práticas psicológicas como instrumentos de castigo, tortura ou qualquer forma de violência (Resolução No 009, 2018, art. 31).

Pontua que "as psicólogas e os psicólogos não poderão elaborar, validar, traduzir, adaptar, normatizar, comercializar e fomentar instrumentos ou técnicas psicológicas, para criar, manter ou reforçar preconceitos, estigmas ou estereótipos" (Resolução No 009, 2018, art. 32) e que

[...] a psicóloga e o psicólogo, na realização de estudos, pesquisas e atividades voltadas para a produção de conhecimento e desenvolvimento de tecnologias, atuarão considerando os processos de desenvolvimento humano, configurações familiares, conjugalidade, sexualidade, orientação sexual, identidade de gênero, identidade étnico-racial, características das pessoas com deficiência, classe social, e intimidade como construções sociais, históricas e culturais (Resolução No 009, 2018, art. 33).

Há, portanto, que se perguntar, em relação aos direitos humanos, não somente quais (ou o que) são esses direitos, mas também o que é o humano, tarefa à qual a Psicologia não pode se esquivar. Indagações que, associadas à avaliação psicológica, podem ser desdobradas em três instâncias coexistentes: 1 Quanto aos requisitos éticos essenciais: (a) $\mathrm{O}$ (s) instrumento(s) que utilizamos para avaliar está(ão) em conformidade com os dispositivos legais (Constituição Federal, Código Civil e Penal e legislações complementares) do país e tratados internacionais aos quais o Brasil é signatário?; (b) Há incompatibilidade do objeto da avaliação psicológica com as diretrizes aprovadas pelos Congressos Nacionais de Psicologia (CNP)?; (c) Há coerência, no processo de avaliação psicológica, com as demais políticas do Sistema Conselhos de Psicologia?; 2 - Quanto ao teste: (a) O instrumento estigmatiza algum grupo social (gênero, orientação sexual, identidade de gênero, étnico-racial, geográfica, geracional, classe socioeconômica)?; (b) O instrumento reflete estereótipos a respeito desses grupos?; (c) O instrumento sugere implícita e/ou explicitamente que as características avaliadas são causadas por algum atributo intrínseco desses grupos?; (d) Os itens contemplam a diversidade sócio-histórico-cultural brasileira dos grupos citados?; 3 - Quanto à amostra: (a) A amostra representa a diversidade sócio-histórico-cultural brasileira: se não, isso está explícito no manual como limitação?; (b) Quanto ao manual, processo de interpretação e aplicação do instrumento: o processo de aplicação do instrumento reforça estigmas e/ou pode ter efeitos negativos nas populações que tem como alvo? As características avaliadas refletem estereótipos em relação a esses grupos? A linguagem da interpretação apresenta vieses discriminatórios?

\section{Considerações finais}

Partimos, então, do pressuposto de que o mundo, os objetos que nele existem, os sujeitos que nele habitam e suas práticas sociais são produzidas historicamente, não tendo, portanto, uma existência em si, coisas já dadas, essência ou natureza. Hegemonicamente produzem-se subjetividades normalizadas, articuladas por sistemas hierárquicos, por sistemas de valores e sistemas de submissão, internalizados pela recusa de entendimento de que a desigualdade estrutural do país constitui modos de sermos humanos. Há, assim, a necessidade de articular o processo avaliativo com a afirmação da diversidade que nos constitui, para a efetiva afirmação de direitos locais, descontínuos, fragmentários, processuais, em constante construção, produzidos pelo cotidiano de nossas práticas e ações - e avaliações.

Avaliações que contemplem a história das condições que possibilitam a interferência de forças sociais diversas, em contextos específicos e condições histórico-sociais concretas, que impulsionam, retardam ou, de algum modo, modificam o desenvolvimento e a efetividade prática dos direitos humanos na sociedade, produzindo diferentes modos de humanos.

O que pretendiam e por quais causas lutavam os franceses quando, em nome dos direitos humanos, construíram em 1789 sua revolução? O que pretendemos nós, nos 15 anos do Satepsi e nos 70 anos da Declaração Universal dos Direitos Humanos, publicarmos a Resolução n ${ }^{\circ} 09$ de 2018, do Conselho Federal de Psicologia? O que queremos nós, ao afirmar a indissociabilidade entre avaliação psicológica e direi- 
tos humanos? Como nos diz Trindade (2002): “Tão importantes quanto as ideias que a Declaração contém são as ideias que ela não contém" (p. 55). Quais éticas implícitas que, por não ser possível a explicitação, não cabem em nossas resoluções?

Como, enfim, reinventar a prática dos direitos humanos? Se for preciso mudar nossa prática, de que maneira podemos afirmá-la como mudança, para que ela deixe de ser apenas fatos normativos para tornar-se possibilidade, potência e variação de formas de vida?

As Declarações, as Convenções, os Pactos e a própria Constituição Federal não asseguram a efetiva prática dos direitos humanos. A Resolução $\mathrm{n}^{\circ} 09$ de 2018 também não. É necessário, nestes 15 anos, que ultrapassemos os limites do retórico e do abstrato e que o tema "direitos humanos" transversalize concretamente as práticas profissionais. Como afirma Baremblitt (1992): "Entre a letra, a declaração formal de direitos humanos, e a sua efetivação e realização concreta há um considerável espaço ou uma dife- rença notável” (p. 40). E ainda, de acordo com Pelbart (2000): "Como diz Deleuze, os direitos humanos não dizem nada sobre os modos de existência imanentes do homem dotado de direitos. É sobre eles que seria preciso falar, sobre as formas de vida vigentes" (p. 46).

É necessário nos posicionarmos, em concordância com a Resolução no 09/2018 do Conselho Federal de Psicologia, para afirmarmos a indissociabilidade entre direitos humanos e avaliação psicológica. E que, junto a ela, continuemos interrogando e analisando as implicações de cada uma e de cada um de nós nos processos avaliativos. Uma resolução não assegura a efetiva indissociabilidade entre direitos humanos e avaliação psicológica, mas é um bom começo. Continuemos, portanto, indagando a nós mesmos sobre as demandas que colocamos em análise e sobre os efeitos que, dialogicamente, encontram-se presentes nas avaliações que produzimos. E reiteremos a inseparabilidade e a necessidade de que esta seja, definitivamente, uma questão para todas e todos nós.

\section{Referências}

Baremblitt, G. F. (1992). Compêndio de análise institucional e outras correntes: Teoria e prática. Rio de Janeiro, RJ: Rosa dos Tempos.

Barros, L. P., \& Kastrup, V. (2009). Cartografar é acompanhar processos. In: E. Passos, V. Kastrup, \& L. Escóssia (Orgs.), Pistas do método da cartografia: Pesquisa-intervenção e produção de subjetividade (pp. 52-75). Porto Alegre, RS: Sulina.

Bezerra Junior, B. (2006). O normal e o patológico: Uma discussão atual. In: A. N. Souza, \& J. Pitanguy (Orgs.), Saúde, corpo e sociedade (pp. 91-109). Rio de Janeiro, RJ: Ed.UFRJ.

Bicalho, P. P. G. (2013a). Direitos humanos e avaliação psicológica: Pela abertura das caixas pretas que nos constituem. In: Conselho Federal de Psicologia - CFP (Org.), Relatório do ano temático da avaliação psicológica 2011/2012 (pp. 30-36). Brasília, DF: Conselho Federal de Psicologia.

Bicalho, P. P. G. (2013b). Ditadura e democracia: Qual o papel da violência de Estado? In: Conselho Regional de Psicologia do Rio Grande do Sul (Org.), Entre garantia de direitos e práticas libertárias (pp. 13-34). Porto Alegre, RS: 0 autor.

Bicalho, P. P. G. (2015). Direitos humanos e movimentos sociais: Desafios à democracia (e à psicologia) brasileira. In: Associação Brasileira de Psicologia Social (Org.), A psicologia social e os atuais desafios ético-políticos no Brasil (pp. 176-191). Porto Alegre, RS: Abrapso.

Bicalho, P. P. G. (2005). Subjetividade e abordagem policial: Por uma concepção de direitos humanos onde caibam mais humanos (Tese). Instituto de Psicologia, Universidade Federal do Rio de Janeiro, Rio de Janeiro, RJ, Brasil.

Bicalho, P. P. G., \& Barbosa, R. P. B. (2014a). As violações de direitos humanos nas políticas de 'guerra às drogas' no Brasil. In: S. Maciel, W. Lima, \& S. Andrade (Orgs), Saúde mental \& dependência química (2a ed., pp. 169-184). João Pessoa, PB: Ed.UFPB.

Bicalho, P. P. G., \& Barbosa, R. P. B. (2014b). O modo indivíduo nas políticas públicas sobre drogas no Brasil e as encomendas endereçadas à Psicologia. Polis e Psique, 4(2), 230-249. https://doi.org/10.22456/2238-152X.51096

Bicalho, P. P. G., Cassal, L. C. B., Magalhães, K. C., \& Geraldini, J. R. (2009). Formação em psicologia, direitos humanos e compromisso social: A produção micropolítica de novos sentidos. Boletim Interfaces da Psicologia da UFRRJ, 2(2), 20-35. 
Bicalho, P. P. G., Magalhães, K. C., Cassal, L. C. B., \& Geraldini, J. R. (2012). Cinquenta anos de produção do conhecimento: Práticas políticas da pesquisa em Psicologia. Psicologia: Ciência e Profissão, 32(n.spe.), 264-275. https:// doi.org/10.1590/S1414-98932012000500019

Bicalho, P. P. G., \& Reishoffer, J. C. (2017). Exame criminológico no Brasil: da construção de pareceres dos perigosos à análise do perigo dos pareceres. In: E. M. Rosa, \& L. Z. Avellar (Orgs), Psicologia, justiça e direitos humanos (pp. 71-84). Curitiba, PR: Juruá.

Bock, A. M. B. (1999). A Psicologia a caminho do novo século: identidade profissional e compromisso social. Estudos de Psicologia (Natal), 4(2), 315-329. https:// doi.org/10.1590/S1413-294X1999000200008

Canguilhem, G. (2009). O normal e o patológico. Rio de Janeiro, RJ: Forense Universitária.

Cesar, J. M.; Silva, F. H., \& Bicalho, P. P. G. (2013). O lugar do quantitativo na pesquisa cartográfica. Fractal: Revista de Psicologia, 25(2), 357-372. https://doi.org/10.1590/S1984-02922013000200009

Conselho Federal de Psicologia - CFP. (2013). Cartilha de avaliação psicológica. Brasília, DF: Conselho Federal de Psicologia.

Conselho Regional de Psicologia de São Paulo (2011). Exposição 50 anos da psicologia no Brasil: A história da psicologia no Brasil. São Paulo, SP: o autor.

Costa, A. B., \& Nardi, H. C. (2013). Diversidade sexual e avaliação psicológica: os direitos humanos em questão. Psicologia: Ciência e Profissão, 33(n.spe), 124-137.

Damasio, B. F. (2013). Contribuições da Análise Fatorial Confirmatória Multigrupo (AFCMG) na avaliação de invariância de instrumentos psicométricos. Psico-USF, 18(2), 211-220. https://doi.org/10.1590/S1413-82712013000200005

David, J. S., Pedro, R. M. L. R., \& Bicalho, P. P. G. (2014). Políticas de pesquisa: da Verdade à produção de verdades. Ayvu: Revista de Psicologia, 1(1), 126-141. https:// doi.org/10.22409/ayvu.vlil.16

Deleuze, G. (1976) Nietzsche e a filosofia. Rio de Janeiro, RJ: Rio/Semeion.

Herkenhoff, J. B. (1997). Direitos humanos: A construção universal de uma utopia. Aparecida do Norte, SP: Santuário.

Patto, M. H. S. (1997). Para uma crítica da razão psicométrica. Psicologia USP, 8(1), 47-62.

Pelbart, P. P. (2000). Direitos IV. In: Conselho Federal de Psicologia - CFP. (Org.), Psicologia, direitos humanos e sofrimento mental (pp. 45-52). São Paulo, SP: Casa do Psicólogo.

Ramos, S. I. S., \& Bicalho, P. P. G. (2012). Avaliação psicológica em varas de família: “ubuescas" proteções à infância. Polis e Psique, 2(2), 63-80. https://doi.org/10.22456/2238-152X.36666

Reishoffer, J. C., \& Bicalho, P. P. G. (2017). Exame criminológico e psicologia: Crise e manutenção da disciplina carcerária. Fractal: Revista de Psicologia, 29(1), 34-44. https://doi.org/10.22409/1984-0292/v29i1/1430

Reppold, C. T. (2011). Qualificação da avaliação psicológica: critérios de reconhecimento e validação a partir dos direitos humanos. In: Conselho Federal de Psicologia - CFP (Org.), Ano da avaliação psicológica: Textos geradores (pp. 21-28). Brasília, DF: Conselho Federal de Psicologia.

Resolução No 007, 14 de junho de 2003. Institui o Manual de Elaboração de Documentos Escritos produzidos pelo psicólogo, decorrentes de avaliação psicológica e revoga a Resolução CFP 17/2002. Brasília, DF: Conselho Federal de Psicologia.

Resolução No 009, de 25 de abril de 2018. Estabelece diretrizes para a realização de Avaliação Psicológica no exercício profissional da psicóloga e do psicólogo, regulamenta o Sistema de Avaliação de Testes Psicológicos - SATEPSI e revoga as Resoluções n 002/2003, no 006/2004 e n 005/2012 e Notas Técnicas nº 01/2017 e 02/2017. Brasília, DF: Conselho Federal de Psicologia.

Resolução No 010, de 21 de julho de 2005. Aprova o Código de Ética Profissional do Psicólogo. Brasília: Conselho Federal de Psicologia.

Trindade, J. D. L. (2002). História social dos direitos humanos. São Paulo, SP: Fundação Peirópolis.

Yamamoto, O. H. (2007). Políticas sociais, 'terceiro setor' e 'compromisso social': Perspectivas e limites do trabalho do psicólogo. Psicologia \& Sociedade; 19(1), 30-37. https://doi.org/10.1590/S0102-71822007000100005

Yamamoto, O. H., \& Amorim, K. M. O. (2010). Estudando a profissão de psicólogo no Brasil: introdução. In: O. H. Yamamoto, \& A. L. F. Costa (Orgs.), Escritos sobre a profissão de psicólogo no Brasil (pp. 15-31). Natal, RN: EdUFRN. 


\section{Pedro Paulo Gastalho de Bicalho}

Professor associado do Instituto de Psicologia da Universidade Federal do Rio de Janeiro, vinculado ao Programa de Pós-Graduação em Psicologia e ao Programa de Pós-Graduação em Políticas Públicas em Direitos Humanos. Rio de Janeiro - RJ. Brasil. Bolsista de produtividade em pesquisa (CNPq).

E-mail:ppbicalho@ufrj.br

Erick da Silva Vieira

Discente do curso de graduação em Psicologia da Universidade Federal do Rio de Janeiro. Rio de Janeiro - RJ. Brasil. E-mail: ericksilvieira@gmail.com

Endereço para envio de correspondência:

Av. Pasteur, 250 - Pavilhão Nilton Campos, campus Praia Vermelha, Urca- Rio de Janeiro / RJ

CEP 22290-902

Recebido 15/08/2018

Aprovado 17/08/2018

Received $08 / 15 / 2018$

Approved 08/17/2018

Recibido 15/08/2018

Aceptado 17/08/2018

Como citar: Bicalho, P. P. G., \& Vieira, E. S. (2018). Direitos humanos e avaliação psicológica:

Indissociabilidade do compromisso ético-político profissional. Psicologia: Ciência e Profissão, 38(n.spe), 147-158. https://doi.org/10.1590/1982-3703000211836

How to cite: Bicalho, P. P. G., \& Vieira, E. S. (2018). Human rights and psychological assessment: Inseparability of the professional ethical-political commitment. Psicologia: Ciência e Profissão, 38(n.spe), 147-158.

https://doi.org/10.1590/1982-3703000211836

Cómo citar: Bicalho, P. P. G., \&Vieira, E. S. (2018). Derechos humanos y evaluación psicológica:

Inseparabilidad del compromiso ético-político profesional. Psicologia: Ciência e Profissão, 38(n.spe), 147-158.

https://doi.org/10.1590/1982-3703000211836 